\title{
Digitalization of Education in Ukraine on the Basis of Innovation and Investment
}

\author{
Kraus Nataliia M. ${ }^{1}$, Osetskyi Valerii L. ${ }^{2}$ and Kraus Kateryna M. ${ }^{1}$ \\ ${ }^{1}$ Borys Grinchenko Kyiv University, Kyiv, Ukraine \\ ${ }^{2}$ Taras Shevchenco National University of Kyiv, Kyiv, Ukraine
}

Keywords: Digital Education, Innovation, Educational Services, Digitalization.

\begin{abstract}
Purpose of the article is to identify specific features of digital education, to reveal its content and to find out main new digital trades. Methods of the article: generalization - in studying the nature of digital education, the prerequisites for the reform of the principles of digital technologies. Results. In scientific publications substantiates the essence of digitization of education, as such, based on the use of digital computer technologies in the educational process. Successful outcome of digital education is the expected successful functioning of the economy within the "digital triangle": digital citizenship, digital creativity and digital entrepreneurship. Main resource of digital education is information. Conclusions. The article focuses on the description of digital competences that a specialist must possess. Comprehensive review of a number of tasks that are posed to the authorities at all levels of economic aggregation and urgently needed to accelerate the digitization of education.
\end{abstract}

\section{Relevance of Research Topic}

The emergence of digital education is due to the development of technologies that promote the transformation of the educational system, the creation of virtual-real ties between education, science, society, government, business and innovation. It is digital education that promotes the effective cooperation of a large number of teachers, students, students, teachers in the field of gaining new knowledge, gaining digital competencies.

Digital education makes an effective and transparent educational process, offers new tools for scientific and educational cooperation. Digital education implies a radical transformation of the methodology of providing educational services through the integration of ICT technology into the educational process and the use of the Internet culture of openness and the exchange of information and knowledge, thereby producing digital competences.

\section{Formulation of the Problem}

The reform and system modernization of the Institute of Education, the basis of which is increasingly the use of modern digital technology, highlights the issue of the formation of digital 
competencies. It is the processes that are taking place today that allow putting an agenda on the formation of a new model of education, where relations concerning the processing, storage, transmission and use of a growing amount of data that accelerate innovation and digitalization of the Ukrainian economy are becoming of paramount importance.

\section{Analysis of Recent Research and Publications}

With the study of the general aspects of structural changes and the complex modernization of the system of education and science in the direction of their innovation and digitalization, and problems of adaptation of modern education of Ukraine to the challenges of the global space associated names A. Babkin, V. Groisman, A. Dobrynin, M. Zgurovsky, P. Kupriansky, A. Petrenko, A. Raykova, V. Suhomlin, L. Ustinova and other.

\section{Presenting Main Material}

Digital Education is education that provides innovative communication opportunities, the exchange of knowledge, ideas and experiences between a teacher and a student through the use of digital computer technologies.

Digital education is not a trend, but a way of development, progress and transition to a new civilization stage in secondary and high school [1]. The content and purpose pursued by reformers in the digitalization of education is to apply software and IT solutions that will make learning (education) more qualitative and interesting, comfortable living in cities, doing business easier, and lead to a new level of interaction communities and authorities.

Digitization of education enables to intensify the educational process, increase the speed and quality of perception, understanding and assimilation of knowledge. The main resource of digital education is information. Digital education already changes the traditional system of education in the direction of forming its new quality (Figure 1).

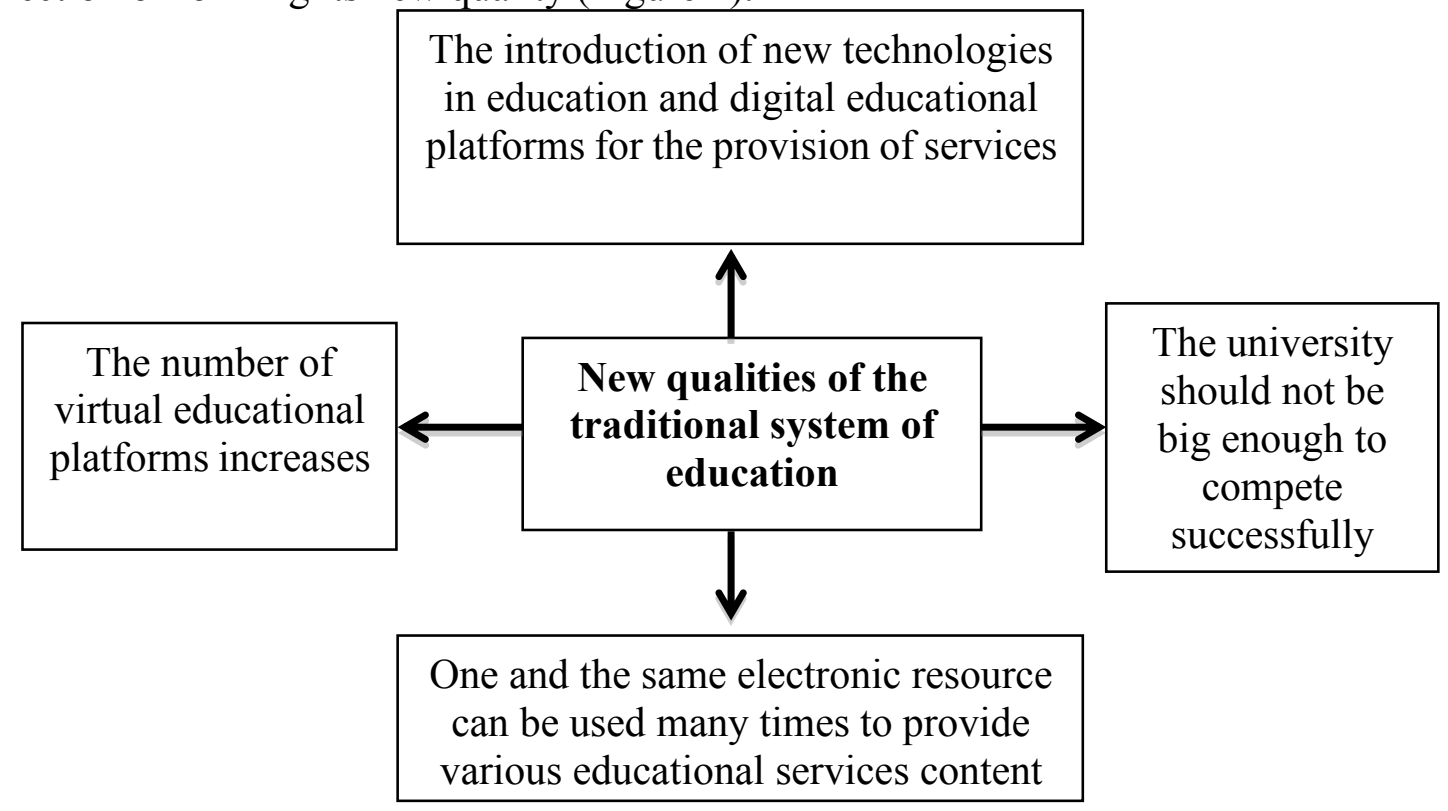

Figure 1. New Qualities of the Traditional System of Education as a Result of Digitalization in Ukraine (made by authors)

Educational digital technologies allow the learning process to be mobile, differentiated, individual, 
interesting and rich. At the same time, educational new technologies do not replace the teacher, but complement it (Figure 2).

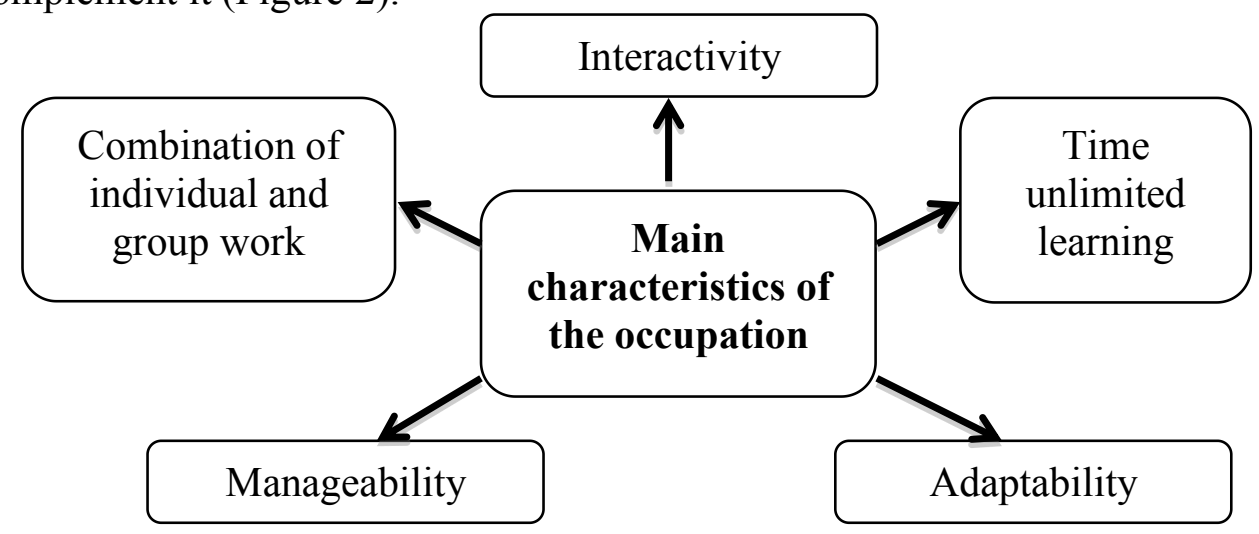

Figure 2. Main Characteristics of the Occupation on the Basis of Innovation and Investment (made by authors)

Educational digital technologies open up new opportunities for the teacher, allowing them, together with students, to enjoy communication and learning in the course of their studies.

Educational technologies allow the teacher to automate most of their work, freeing human resources to search, communication, individual work with students, enable instant feedback, improve the management of learning and research processes and education in general.

Digital competence has a number of structural components that must be owned and managed by the individual as a result of the successful implementation of digital education practice.

Digital competence involves confident, critical and responsible use and interaction with digital technology for learning, work and community participation [2]. Individuals need to understand how digital technologies can support communication, creativity and innovation, be aware of their capabilities, limitations, implications and risks.

Individuals with digital competences should understand the general principles, mechanisms and logic underlying the emerging digital technologies, as well as know the basics of the operation and use of different devices, programs and networks (Figure 3).

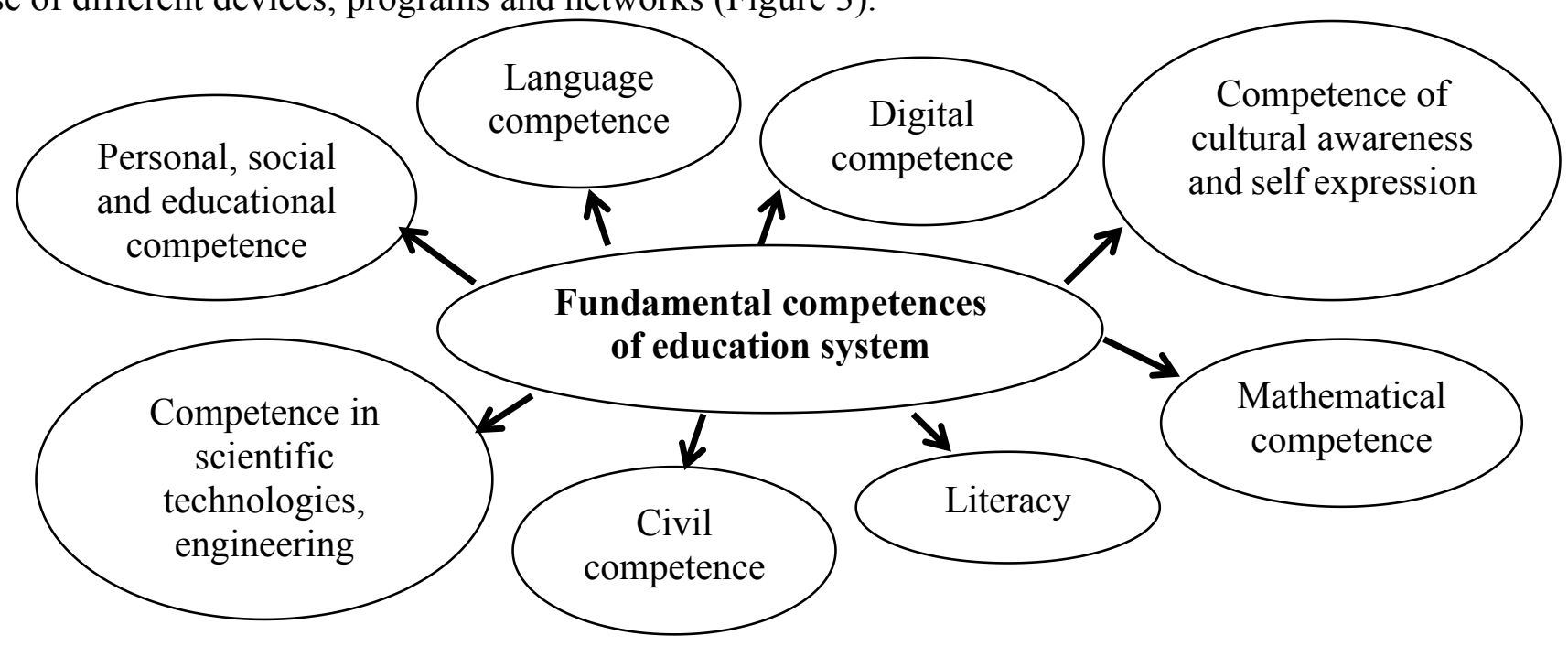

Figure 3. Fundamental Competences as a Result of Reforming of Education System of Ukraine on the Basis of Innovation and Investment (made by authors)

In order to realize the plan, the establishment of digital education in Ukraine and the expansion of 
the list of existing competencies, it is necessary to solve a number of problems, among which:

1. Introduction of a competency-based approach, cross-platform (cross-platform) digital competence, that is, when the study of subjects takes place through the use of "digital" technologies, in the course of which, digital skills develop.

2. Increasing the share and improving the quality of training of specialists in the field of information and communication technologies (ICT):

- Increasing the state order for the training of ICT specialists;

- Involving girls and women in the ICT sphere.

3. Development of the system of "social and innovative elevators" in the ICT sphere, including:

- Informing schoolchildren and students about possible internship and passing the practice in ICT companies;

- Timulating the development of youth ICT entrepreneurship.

4. Measurement and certification of digital skills. Adaptation of the measurement methodology and implementation of the independent certification of the level of digital skills in accordance with the needs of the labor market.

5. Harmonization of the regulatory framework that regulates the certification of digital skills among civil servants, pedagogical staff, other classes, with international requirements, as well as a regulatory framework for additional payroll taxes in the context of confirming digital competencies.

6. Updating the state classifier of professions, that is, developing and approving the list of "digital" professions (based on labor market requirements, modern "digital" trends), their introduction in higher education institutions.

Among the modern "digital" professions that are currently relevant and sought after in the world labor market in the leading countries of the world there are quite a lot of extremely interesting ones (Figure 4).

The key changes that are being observed today in Ukrainian education are the following:

- Universities not only need to provide the educational process, but also become a platform for innovation, which is impossible without merging with science and practice.

- Pool of resources for realization of joint projects, creation of scientific and educational on-line platforms.

- There was the possibility of building personalized educational trajectories.

- Development of a level system of thematic modules.

- Along with traditional education, the society began to use non-traditional, which can be explained by the growth of their competencies to innovations.

Distant form of learning is becoming more and more popular, which is facilitated by the development of information technologies and communications. Digital learning helps to increase the virtual mobility of students, enabling students of Ukrainian universities to study in universities of other countries and take internships there. Digitization of educational services in Ukraine allows to compete adequately within the limits of a single European educational space. 


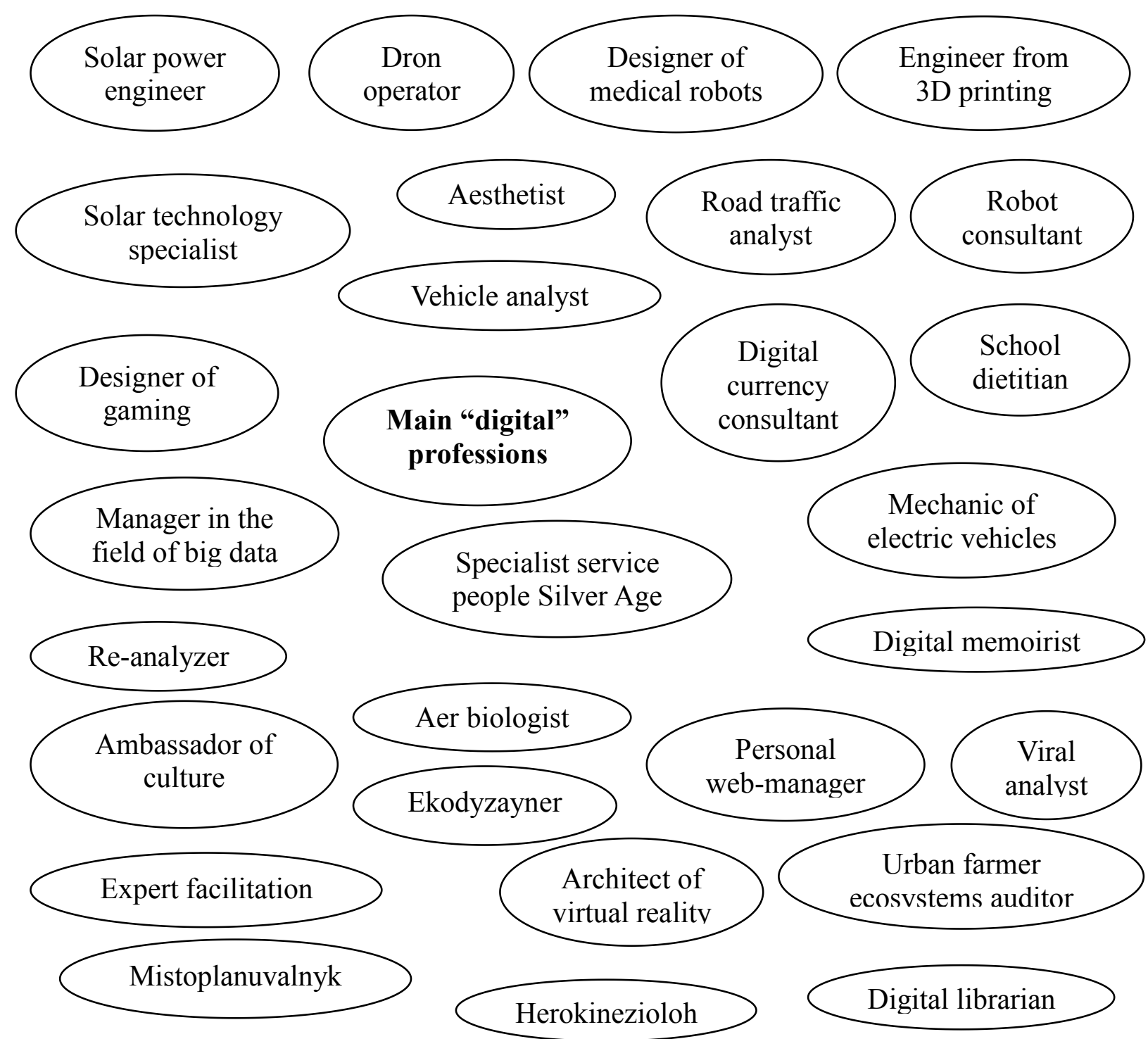

Figure 4. Modern "Digital" Professions in the Wourld (made by authors)

\section{Conclusion}

In summary, we note that digital education is an accelerator of the socio-economic life of society in the modern world and is capable of rapidly increasing the GDP of the country. However, in this case there should be no pauses and even paradoxes. The pragmatism of organizational and institutional action, along with social responsibility, should be at the heart of the institutional provision of digital competences in the field of higher education.

Institutionalization of modern economic order in the direction of the formation and development of digital competences should take into account the peculiarities of the evolution of social values that dominate the economic order of the present, and are based on a quality institution of education and creative innovators.

Despite the scale of the scientific achievements that already exist, it is still important to carry out in the future research aimed at developing a roadmap for the digital transformation of education in Ukraine, with the aim of forming a digital society based on this knowledge, for which members have digital skills and higher education in the latest specialties. In addition, digital education should be 
"institutionalized", that is, in the form of standards, norms and rules. And this phase is quite lengthy in time and requires the addition of a large number of leading scholars, researchers and practitioners.

\section{References}

[1] Key competencies for lifelong learning 2018 - Digital competency. Distance and mixed computer science education. Available at: http://dystosvita.blogspot.com/2018/01/2018.html (accessed 18 May 2019).

[2] Digital adzhda of Ukraine 2020 ("Digital agenda" - 2020). Conceptual basis (version 1.0). Priority areas, initiatives, projects of "digitalization" of Ukraine by 2020". HITECH office. Available at: https://ucci.org.ua/uploads/files/58e78ee3c3922.pdf (accessed 22 May 2019). 